http://dx.doi.org/10.21611/qirt.2014.202

\title{
Performance tests of thermal imaging systems to assess their suitability for quantitative temperature measurements
}

Aaron Whittam, Rob Simpson, Helen McEvoy

National Physical Laboratory, Teddington, United Kingdom, TW11 OLW

\begin{abstract}
The number of thermal imagers being used for absolute temperature measurement in industry has increased dramatically in the past few years. Due to this it is vital that we have a greater understanding of the performance and limitations of thermal imagers for manufacturing, design and calibration purposes, in particular for applications where they are being used for quantitative temperature measurements. A metrological assessment of six thermal imagers was carried out over their full temperature range using the National Physical Laboratory (NPL) high performance standard blackbody reference sources to identify their accuracy and repeatability. The size-of-source effect, temperature drift due to warm up, image non-uniformity, effects of ambient temperature changes and distance effects were also investigated. Results show that temperature errors for five out of the six imagers fell outside of the manufacturers' stated uncertainty at a distance of $1.0 \mathrm{~m}$ from the blackbody reference source. Additionally, a number of the imagers showed poor performance with regard to image non-uniformity, drift, size of source and distance effects. This has implications when the imagers are used for in situations where accurate temperature measurements or temperature differences are required.
\end{abstract}

\section{Introduction}

Traditionally thermal imagers have been used for qualitative measurements only, such as for target recognition and routine maintenance checks (looking for hot spots). Thermal imagers have the advantage compared to single spot radiation thermometers in that they display a temperature map of the whole scene. With the commercialisation, advances in technology and subsequent drop in price of thermal imagers over the past 10 years an increasing number of sectors are using thermal imagers for quantitative temperature measurement, rather than single spot radiation thermometers which have been more traditionally used. It is important that thermal imagers have been properly evaluated for their suitability as quantitative temperature measurement devices and they have been traceably calibrated in terms of the International Temperature Scale of 1990 (ITS-90) [1] using high quality blackbody calibration sources.

Therefore this paper has assessed the suitability of thermal imagers for quantitative temperature measurement by carrying out a temperature calibration and also assessing factors that could influence the temperature measurement accuracy such as image non-uniformity, distance effect (change in imager reading with changing distance from the calibration source), size of source effect (change in imager reading with changing source size), influence of changing ambient temperature and warm up time.

Six commercially available thermal imagers from different manufacturers and with a range of different specifications were chosen in order to evaluate a representative cross-section of thermal imagers on sale today. The majority of thermal imagers available for commercial use operate over the wavelength of $7 \mu \mathrm{m}-14 \mu \mathrm{m}$ (long wave infrared (LWIR)) and use an uncooled microbolometer array (MBA). These LWIR uncooled MBAs represent the most popular form of thermal imager on the market, due to lower costs when compared to cooled imagers, but also because objects near room temperature $\left(3^{\circ} \mathrm{C}-30^{\circ} \mathrm{C}\right)$ have a peak emission around $10 \mu \mathrm{m}$ making the imagers slightly more sensitive in this range than short or medium wavelength (MWIR) devices. However, where fast response times or greater detector sensitivity is needed often cryogenically cooled detectors are used. To get a representative sample 5 of the imagers tested were uncooled and operated in the spectral range of $7 \mu \mathrm{m}-14 \mu \mathrm{m}$ and, as a comparison, a research grade MWIR cooled InSb detector based imager was also included. 
Table 1 Manufacturers' technical specification of the 6 thermal imagers.

\begin{tabular}{|c|c|c|c|c|c|c|}
\hline $\begin{array}{l}\text { Thermal } \\
\text { Imager }\end{array}$ & Imager A & Imager B & Imager C & Imager D & Imager E & Imager F \\
\hline Array size & $320 \times 240$ & $160 \times 120$ & $120 \times 120$ & $128 \times 96$ & $160 \times 120$ & $320 \times 256$ \\
\hline NETD/ mK & $<50$ & 80 & $<100$ & 200 & $<70$ & $<20$ \\
\hline $\begin{array}{c}\text { Frame rate/ } \\
\mathrm{Hz}\end{array}$ & 60 & 128 & 9 & 30 & 60 & $1-100$ \\
\hline Focus & Automatic & Manual & Manual & Manual & Manual & Automatic \\
\hline FPA & $\begin{array}{l}\text { Uncooled } \\
\text { MBA }\end{array}$ & $\begin{array}{l}\text { Uncooled } \\
\text { MBA }\end{array}$ & $\begin{array}{l}\text { Uncooled } \\
\text { MBA }\end{array}$ & $\begin{array}{l}\text { Uncooled } \\
\text { MBA }\end{array}$ & $\begin{array}{l}\text { Uncooled } \\
\text { MBA }\end{array}$ & $\begin{array}{c}\text { Cooled InSb } \\
77 \mathrm{~K}\end{array}$ \\
\hline $\begin{array}{c}\text { Spectral } \\
\text { range/ } \mu \mathrm{m}\end{array}$ & 7.5 to 13 & 7.5 to 13 & 7.5 to 13 & 7.5 to 13 & 7.5 to 13 & 3 to 5 \\
\hline $\begin{array}{c}\text { Meas. } \\
\text { Range/ }{ }^{\circ} \mathbf{C}\end{array}$ & -20 to +1000 & -20 to +1500 & -10 to +350 & -10 to +350 & -20 to +650 & -20 to +1000 \\
\hline Accuracy & $\begin{array}{c} \pm 2{ }^{\circ} \mathrm{C} \text { or } \\
\pm 2 \%\end{array}$ & $\begin{array}{c} \pm 2{ }^{\circ} \mathrm{C} \text { or } \\
\pm 2 \%\end{array}$ & $\begin{array}{c} \pm 2{ }^{\circ} \mathrm{C} \text { or } \\
\pm 2 \%\end{array}$ & $\begin{array}{c} \pm 2{ }^{\circ} \mathrm{C} \text { or } \\
\pm 2 \%\end{array}$ & $\begin{array}{c} \pm 2{ }^{\circ} \mathrm{C} \text { or } \\
\pm 2 \%\end{array}$ & $\begin{array}{c} \pm 1{ }^{\circ} \mathrm{C} \text { or } \\
\pm 1 \%\end{array}$ \\
\hline
\end{tabular}

\section{Measurement Procedures}

\subsection{Calibration}

Each thermal imager was calibrated following NPL standard calibration procedure, i.e. in accordance with the procedure usually employed for calibration of single spot radiation thermometers as performed by all EUROMET national measurement institutes (see [2]). The imagers were calibrated using four NPL standard blackbody sources [3] with emissivities $>0.999$, the characteristics of which can be found in table 2 . The temperatures of the blackbodies were determined using calibrated platinum resistance thermometers (PRTs) for temperatures $<600{ }^{\circ} \mathrm{C}$, and a Au-Pt thermocouple for temperature between $600{ }^{\circ} \mathrm{C}-1000^{\circ} \mathrm{C}$, the calibrations for all of which are traceable to the ITS-90. The apertures of the blackbody sources were set to $30 \mathrm{~mm}$ diameter using water-cooled (for temperatures $\geq 50{ }^{\circ} \mathrm{C}$ ) blackened aperture plates.

Table 2 Characteristics of NPL blackbody sources

\begin{tabular}{ccccc}
\hline $\begin{array}{c}\text { Working fluid of } \\
\text { blackbody } \\
\text { sources }\end{array}$ & $\begin{array}{c}\text { Max aperture } \\
\text { diameter } \\
/ \mathbf{~ m m}\end{array}$ & $\begin{array}{c}\text { Temperature } \\
\text { Range } \\
/{ }^{\circ} \mathbf{C}\end{array}$ & $\begin{array}{c}\text { Blackbody Source } \\
\text { Uncertainty }(\boldsymbol{k}=2)\end{array}$ & $\begin{array}{c}\text { Accredited IR thermometer } \\
\text { calibration uncertainty }\end{array}$ \\
\hline Ammonia & 70 & -40 to 50 & 0.04 to 0.07 & 0.1 \\
Water & 40 & 50 to 250 & 0.04 to 0.08 & 0.1 \\
Caesium & 40 & 300 to 600 & 0.04 to 0.07 & 0.2 \\
Sodium & 40 & 600 to 1000 & 0.2 & 0.3 \\
\hline
\end{tabular}

* United Kingdom Accreditation Service (UKAS) Calibration and Measurement Capability (CMC) (accredited uncertainty) values for the calibration of radiation thermometers

The thermal imagers were aligned on the centre of the aperture for each blackbody source, and a small measurement region ( $<15 \mathrm{~mm}$ diameter) at the centre of the imager field of view (FOV) was used for the calibration. The thermal imagers were set at a distance of nominally $1.0 \mathrm{~m}$ from their front lens to the blackbody aperture. Measurements were taken at a minimum of five temperature points over each imager's full range (except imager B which has an upper limit of $1500{ }^{\circ} \mathrm{C}$ ), with repeat measurements taken at a minimum of 3 temperatures. For each temperature at least 12 readings of the imager indicated temperature (taken to be the average indicated temperature over the measurement region) were taken over a two minute period and averaged. For each calibration temperature the difference between the blackbody temperature and the average indicated imager was calculated.

The short term repeatability of the calibration of the thermal imagers was evaluated using the same method as above by calibrating at nominally the same temperatures after a period of one month. The measurement errors (blackbody temperature - indicated imager temperature) were then compared to the initial set of calibration results. 


\subsection{Distance effect}

Imagers are calibrated in the laboratory at a specific distance (for example $1.0 \mathrm{~m}$ ) but are then used at varying, and often considerably longer, distances from the target. To evaluate the effect on the imager temperature reading with varying distance from the source a set of measurements was taken following the same measurement procedure as above but at $0.5 \mathrm{~m}$ from the imager lens to the blackbody. The blackbody aperture diameter was kept at $30 \mathrm{~mm}$, and the measurement regions of the thermal imagers were kept constant throughout their assessment (i.e the same number of pixels in the central region of the detector). However, the thermal imagers were refocused on the aperture at $0.5 \mathrm{~m}$.

\subsection{Size-of-source effect}

The size-of-source effect (SSE) of each of the thermal imagers was determined using the direct method [4] with the blackbody source set at a temperature both near the top (high temperature) and the bottom (low temperature) of the thermal imager's measurement range. The diameter of the aperture of the blackbody was then varied and the displayed temperature, the average over the measurement region, of the thermal imager recorded for each aperture size. The SSE of the thermal imagers was determined as the ratio of the quasi-spectral radiance at a given aperture diameter and the quasi-spectral radiance at the largest aperture diameter.

$$
\begin{gathered}
\operatorname{SSE}(\Phi \mathrm{n})=\frac{Q L\left(\Phi_{n}\right)}{Q L\left(\Phi_{M A X}\right)} \\
Q L(\Phi)=\frac{1}{e^{\frac{c_{2}}{T \lambda}}-1}
\end{gathered}
$$

Where $Q L$ is the quasi-spectral radiance, $\Phi$ is the aperture diameter, $c 2$ is the second radiation constant, $\lambda$ is the mean operational wavelength of the imager (taken to be the mid-point of the manufacturer's stated spectral band) and $T$ is the temperature reading of the imager with aperture $\Phi$.

\subsection{Warm-up effect}

The warm-up effect was evaluated by measuring the change of displayed temperature of each thermal imager over a 30 minute period straight after the thermal imager was switched on. The imagers were focused on a blackbody cavity of nominally $30 \mathrm{~mm}$ diameter at a distance of $1.0 \mathrm{~m}$. The effect was investigated at the top and bottom of each imager's temperature range, where the effects would be most prominent. ${ }^{1}$

\subsection{Image non-uniformity}

The non-uniformity of the thermal imagers' displayed apparent temperature were evaluated using the planar method [5] by splitting the thermal imagers' full FOV into 17 sub-sections figure 1 . The thermal imager was then aligned on the blackbody, at a distance of $0.5 \mathrm{~m}$, so that the image of the blackbody was central within each sub-section, the measurement region was positioned centrally within the blackbody image, and the average indicated temperature displayed over the measurement region was recorded along with the temperature of the blackbody ${ }^{2}$.

Fig. 1 Imager non-uniformity sub-sections

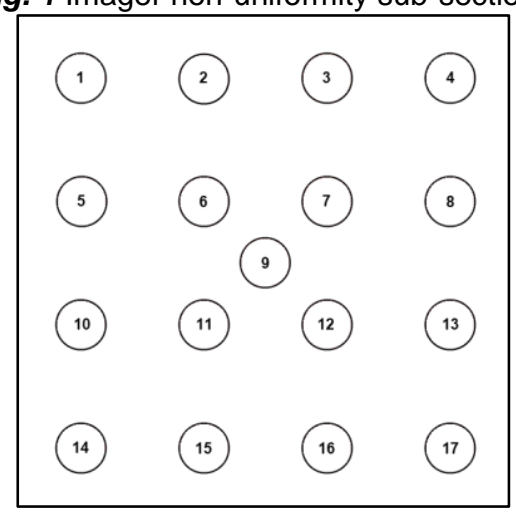

\footnotetext{
${ }^{1}$ This test could not be carried out on imager $C$ as it was unavailable at the time of testing.

${ }^{2}$ This test could not be carried out Imager $C$ or $D$ as the measurement region cannot be moved from the central region of the FOV.
} 


\subsection{Ambient temperature conditions}

The effect of changing ambient temperature condition was investigated over a limited ambient temperature range of $18{ }^{\circ} \mathrm{C}$ to $25^{\circ} \mathrm{C}$ and blackbody temperatures at a number of temperatures over each of the thermal imager's ranges. Ambient conditions could only be tested in this limited range due to limitations of the laboratory's temperature control. Again the average imager indicated temperature over the measurement region was compared to the temperature of the blackbody source. Measurements were taken with the imagers at a distance of $1.0 \mathrm{~m}$ and $0.5 \mathrm{~m}$ from the calibration source.

\section{Results}

\subsection{Calibration}

Figure 2 shows the results from the calibration where the measurement error, $\Delta T$, is plotted against the average blackbody temperature, $\mathrm{T}_{90}$.

$$
\Delta T=T_{90}-T_{\text {imager }}
$$

The solid line represents the manufacturers' stated uncertainties, namely $\pm 2{ }^{\circ} \mathrm{C}$ or $2 \%$ for all imagers (except for imager $\mathrm{F}$ which is $\pm 1{ }^{\circ} \mathrm{C}$ or 1\%) and the dashed line represents the NPL's accredited Calibration and Measurement Capability (accredited uncertainty) for radiation thermometer calibrations. The errors bars represent the calibration uncertainties of the thermal imagers $(k=2$, providing a coverage probability of approximately 95\%), and are given as the combined uncertainty of: the NPL standards; the resolution and stability of the imager; the alignment of the imager on the calibration source; and the repeatability of the calibration of the imager over a period of one month (see table 3). There is also an added component of uncertainty due to the imager's size-of-source effect. The greatest sources of uncertainty for all the imagers arose from the SSE of the instruments and their repeatability, both of which will be discussed later. For comparison the calibration results for a single spot infrared radiation thermometer (IRT) are also shown.

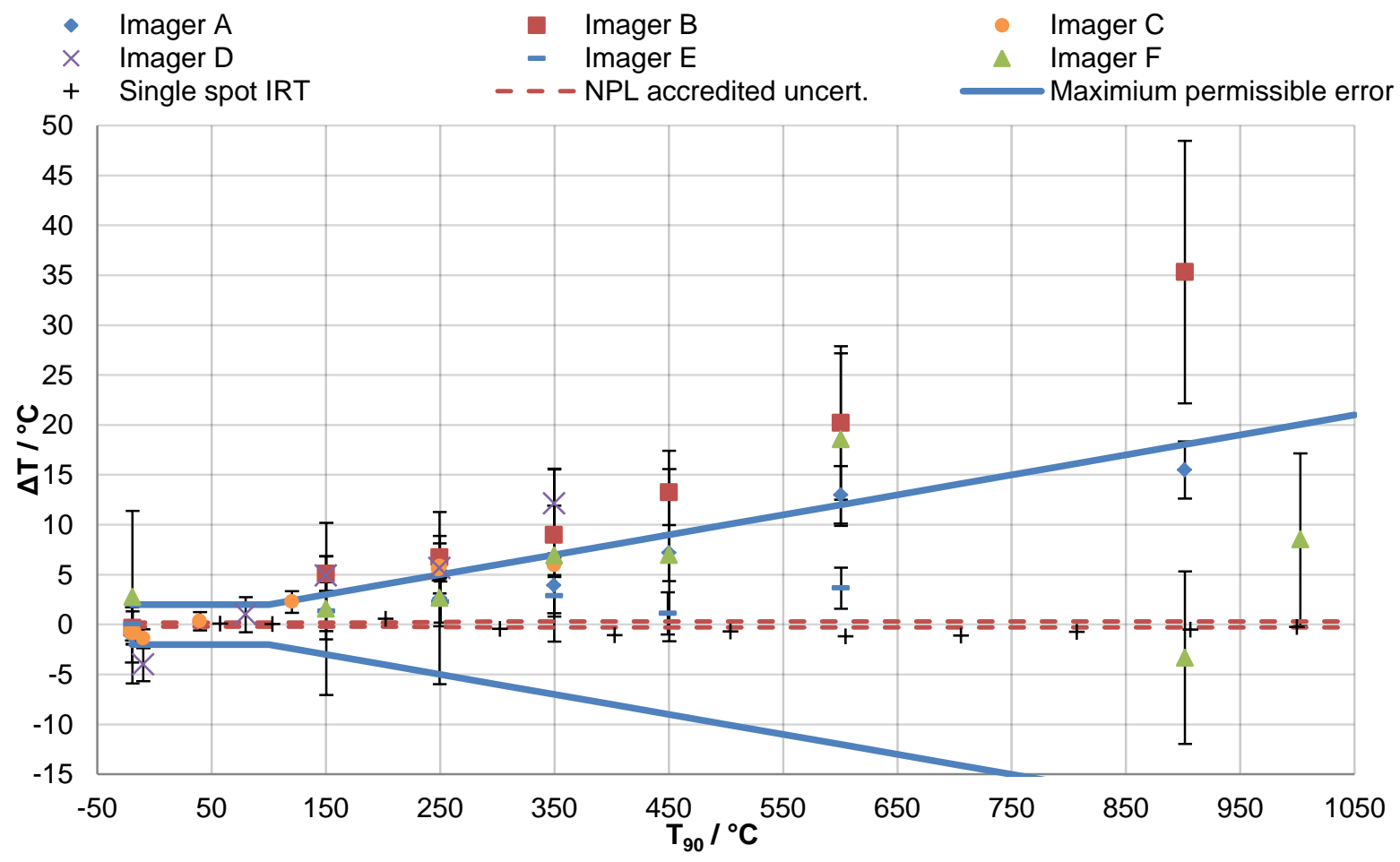

Fig. 2 Calibration results for the thermal imagers at a distance of $1.0 \mathrm{~m}$. The solid line shows most manufacturers' stated uncertainties and the dashed line shows NPL's accredited uncertainty $\left(\leq 0.3^{\circ} \mathrm{C}\right.$ below $\left.1000{ }^{\circ} \mathrm{C}\right)$. For comparison the calibration results for a single spot infrared radiation thermometer are also shown. 
Table 3 Uncertainty budget for the calibration of thermal imagers

\begin{tabular}{|c|c|c|c|}
\hline Source of uncertainty & Type & $\begin{array}{l}\text { Probability } \\
\text { Distribution }\end{array}$ & Divisor \\
\hline Reference source & B & $\mathrm{N}$ & 2 \\
\hline $\begin{array}{l}\text { Short term stability of } \\
\text { reference source }\end{array}$ & A & $\mathrm{N}$ & $\sqrt{ } \mathrm{n}$ \\
\hline $\begin{array}{l}\text { Short term stability of } \\
\text { thermal imager output }\end{array}$ & A & $\mathrm{N}$ & $\sqrt{ } \mathrm{n}$ \\
\hline Resolution of thermal imager & B & $\mathrm{R}$ & $\sqrt{3}$ \\
\hline $\begin{array}{l}\text { Reproducibility of SSE } \\
\text { correction }\end{array}$ & A & $\mathrm{N}$ & $\sqrt{ } \mathrm{n}$ \\
\hline Alignment & B & $\mathrm{R}$ & $\sqrt{3}$ \\
\hline $\begin{array}{l}\text { Repeatability of thermal } \\
\text { imager calibration }\end{array}$ & B & $\mathrm{R}$ & $\sqrt{3}$ \\
\hline
\end{tabular}

Results of the calibration show that all but one imager, imager $\mathrm{E}$, had at least one measurement which fell outside of the manufacturers stated uncertainty of $\pm 2{ }^{\circ} \mathrm{C}$ or $2 \%$ whichever is greatest ${ }^{3}$. The poorest performing imager was imager $\mathrm{B}$, having all but one point $\left(-20^{\circ} \mathrm{C}\right)$ outside of the manufacturer's maximum permissible error, whilst imager $\mathrm{E}$ performed the best, having all measurement points within the manufacturer's stated uncertainty. Both imagers B and $\mathrm{E}$ have the same array size and type, operate over the same spectral range, have similar stated noise-equivalent temperature difference as stated by the manufacturers and are in the same price bracket. Therefore it is difficult to see how a user could judge how an imager will perform purely from the manufacturer's specifications. In comparison the corresponding results for an existing set of measurements for a commercial single spot infrared thermometer, which has a spectral range of $8 \mu \mathrm{m}$ to $13 \mu \mathrm{m}$ and operates over the temperature range from $-50{ }^{\circ} \mathrm{C}$ to $1000{ }^{\circ} \mathrm{C}$, show differences $\Delta T$ which are $<1.5^{\circ} \mathrm{C}$ up to $1000^{\circ} \mathrm{C}$ : a large step up in performance even from the best performing thermal imager.

\subsection{Repeatability}

The repeatability results show that over a period of one month the measurement drift of the majority of the thermal imagers was relatively small. Table 4 shows the greatest difference in readings (largest difference between initial and repeat calibration results) obtained with each of the imagers along with the calibration (blackbody) temperature at which this largest variation was observed.

Table 4 Maximum difference between repeat readings.

\begin{tabular}{ccc}
\hline $\begin{array}{c}\text { Thermal } \\
\text { Imager }\end{array}$ & $\begin{array}{c}\text { Maximum difference between } \\
\text { initial and repeat measurements } \\
/{ }^{\circ} \mathbf{C}\end{array}$ & $\begin{array}{c}\text { Nominal blackbody } \\
\text { temperature } /{ }^{\circ} \mathbf{C}\end{array}$ \\
\hline A & 1.9 & 600 \\
B & 2.1 & -20 \\
C & 0.9 & 350 \\
D & 2.4 & 250 \\
E & 0.9 & 350 \\
F & 10.1 & 900 \\
\hline
\end{tabular}

There is no clear relationship between the temperatures at which the greatest difference in measurements was seen. The difference for imager A increased as the measurement temperature increased. Imager B had the greatest difference in temperature reading at $-20^{\circ} \mathrm{C}$, but showed no trend in repeatability above this temperature. Imager $\mathrm{C}$ showed the greatest difference at the top of its measurement range, $350^{\circ} \mathrm{C}$, and imager $\mathrm{D}$ had the largest difference at $250{ }^{\circ} \mathrm{C}$. Imager $\mathrm{E}$ showed the greatest difference at $350{ }^{\circ} \mathrm{C}$ which is in the middle of the thermal imager's measurement range, but overall had the best repeatability (see figure 3). Imager F showed a considerable difference between repeat readings, at both the top and bottom of its measurement range as shown in figure 3 . There was a $5.4{ }^{\circ} \mathrm{C}$ difference at blackbody temperature of $-20^{\circ} \mathrm{C}$ and $10.1^{\circ} \mathrm{C}$ at $900^{\circ} \mathrm{C}$, likely caused by heating of the detector at $900{ }^{\circ} \mathrm{C}$ and potentially by a poor signal to noise ratio at $-20^{\circ} \mathrm{C}$.

\footnotetext{
${ }^{3} \pm 1{ }^{\circ} \mathrm{C}$ or $1 \%$ for imager $\mathrm{F}$.
} 
$\triangle$ Imager $\mathrm{E} \times$ Imager $E$ repeat

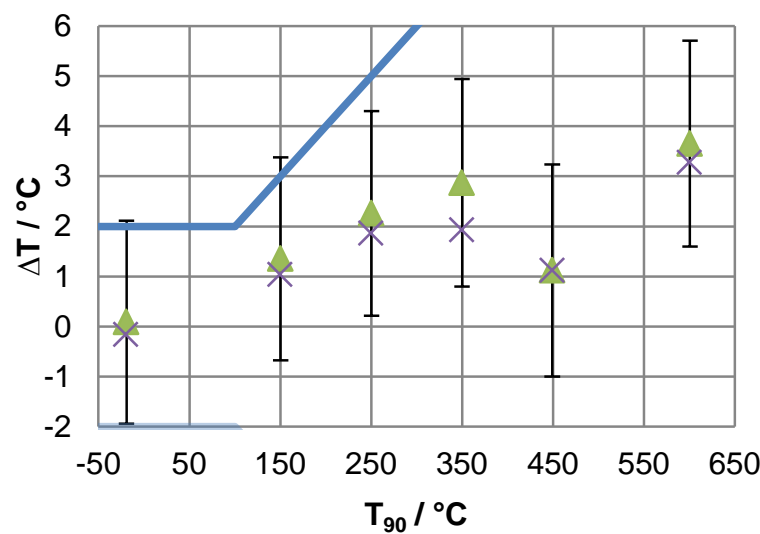

$\triangle$ Imager $F \quad \times$ Imager $F$ repeat

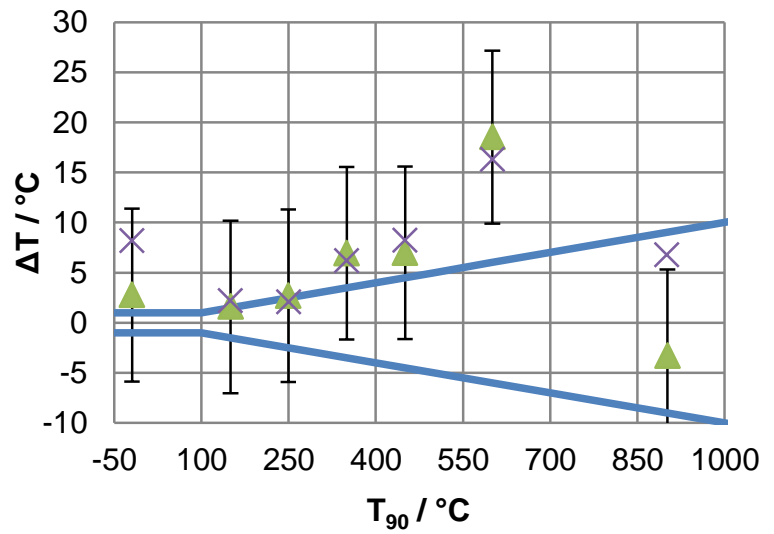

Fig. 3 Repeatability of two thermal imagers; (left) imager E showing good repeatability, (right) imager $F$ showing poor repeatability at the bottom and top of its range. For the $\mathrm{Y}$-axis $\Delta T=T 90-T_{\text {imager }}$. The solid line indicates the manufacturers' stated uncertainty and errors bars represent the NPL calibration uncertainty.

\subsection{Distance effect}

The effect that the imager-to-blackbody distance had on the measurement error (difference between blackbody temperature and indicated imager temperature) of the thermal imagers is shown in figure 4. The results show that there is clearly a difference in measurement values depending on whether the temperature is measured at $0.5 \mathrm{~m}$ or $1.0 \mathrm{~m}$. All of the thermal imagers showed an increasing error in measurement as distance from the blackbody source increased; at $0.5 \mathrm{~m}$ the thermal imager readings were closer to the source temperature. However, at $0.5 \mathrm{~m}$ the difference between the indicated imager temperature and the temperature of the blackbody source still fell outside of the manufacturer's stated uncertainty with three of the imagers. Also at higher temperatures imager $\mathrm{F}$ was found to show no clear correlation between the measurement error at $1.0 \mathrm{~m}$ and $0.5 \mathrm{~m}$, but this may be influenced by the repeatability performance of the imager.

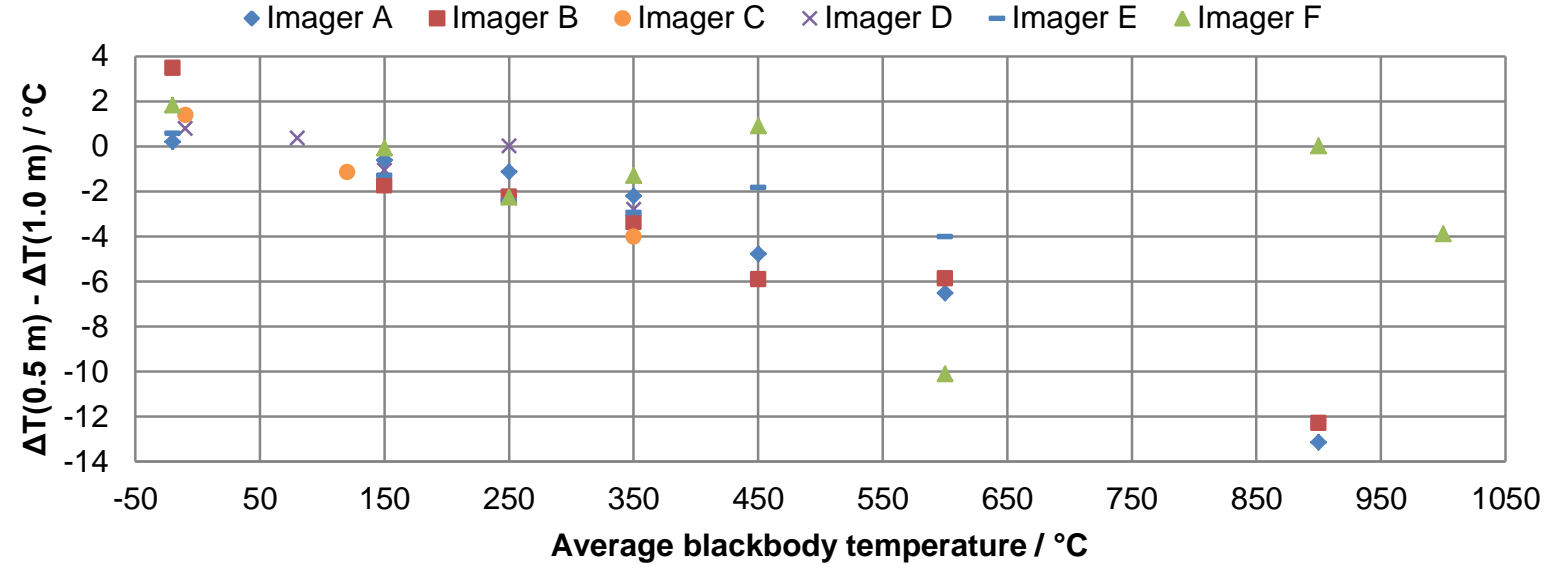

Fig. 4 The effect of distance on thermal imager temperature readings.

These results could be attributed to the thermal imager's size-of-source effect, as the $30 \mathrm{~mm}$ diameter blackbody aperture covers a larger proportion of the thermal imagers' FOV at $0.5 \mathrm{~m}$ compared to $1.0 \mathrm{~m}$. The SSE of single spot radiation thermometers has been well characterised and the causes of SSE are well known $[4,6,7]$. However, the increased number of detectors in thermal imagers can introduce additional errors caused by pixel averaging and cross talking. 


\subsection{Size-of-source effect}

The results of the SSE measurements with the calibration source close to the top temperatures of the imagers' ranges are shown in figure 5 and the results of the low temperature SSE measurements are shown in figure 6. The SSE is the ratio of the quasi-spectral radiance at a given aperture diameter and the quasi-spectral radiance at the largest aperture diameter as described in Section 2.3.

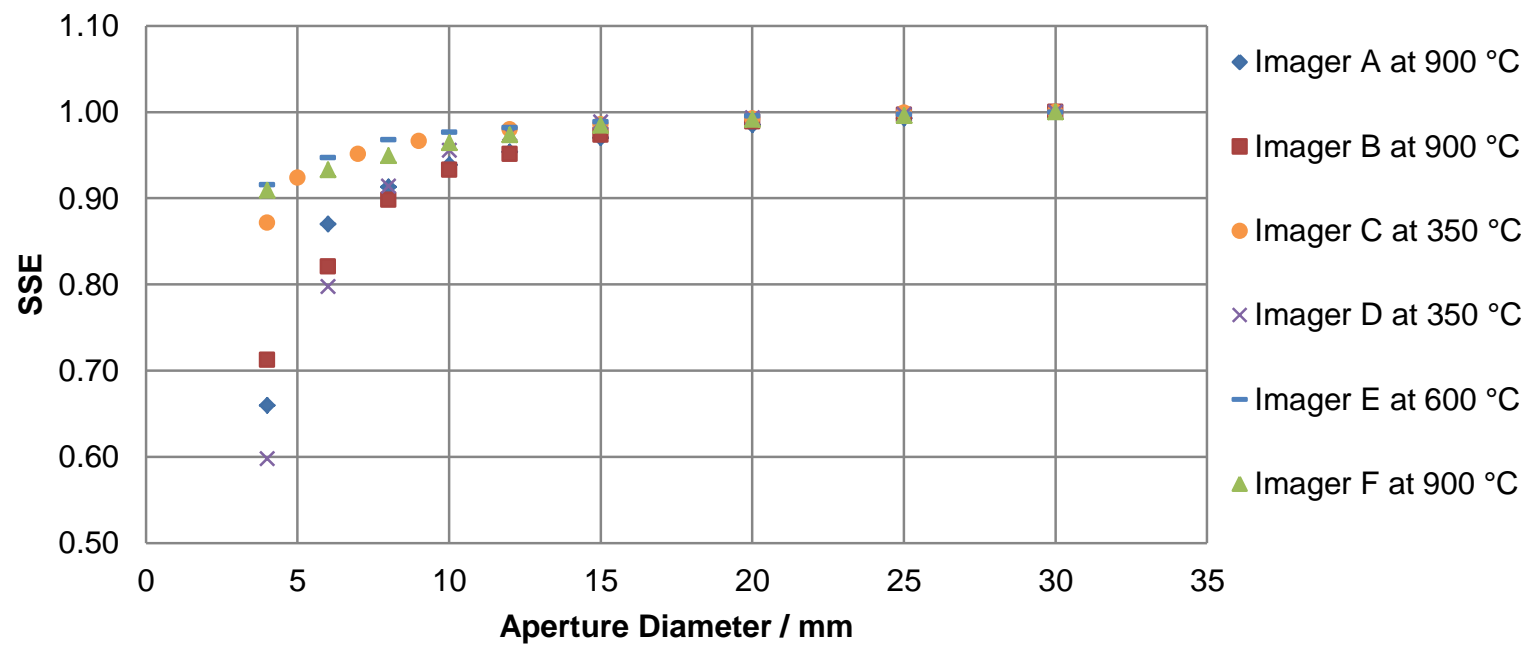

Fig. 5 High temperature SSE results.

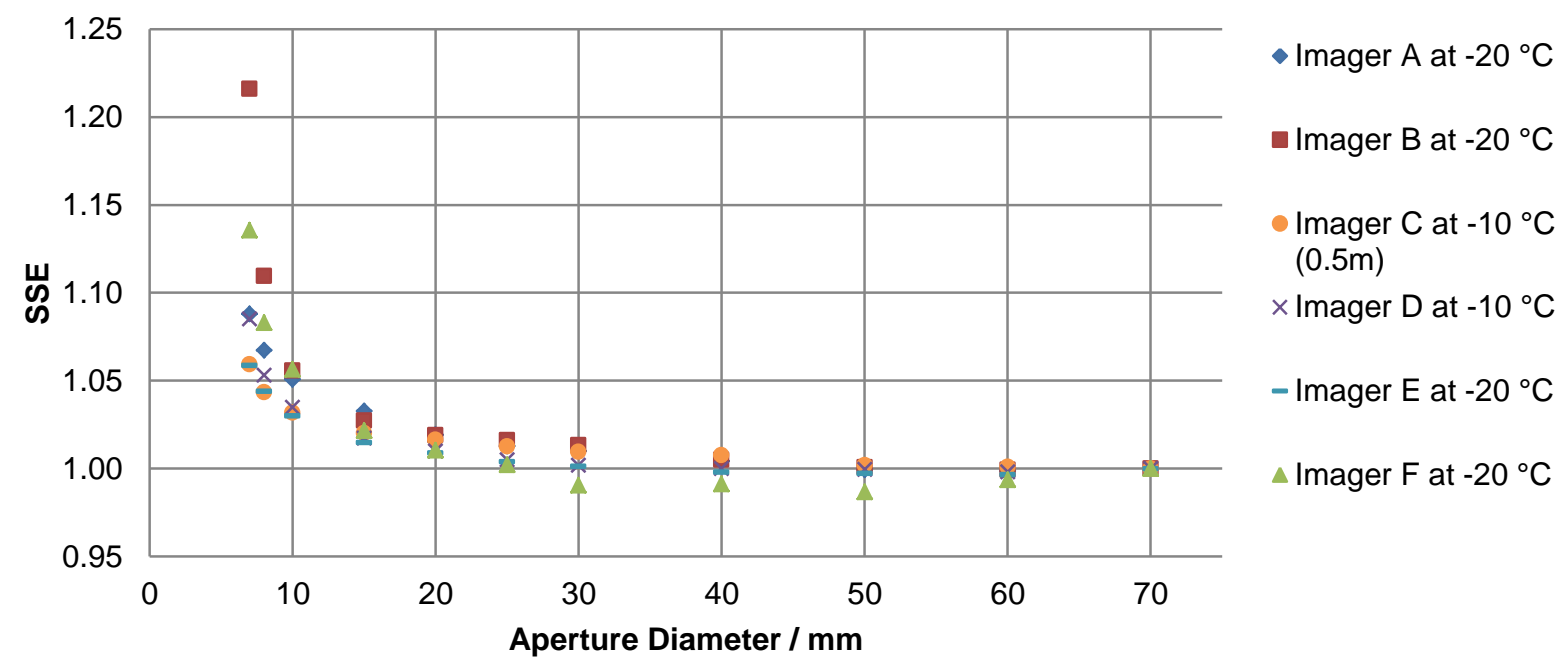

Fig. 6 Low temperature SSE results.

The high temperature SSE results show a large variation in performance of the thermal imagers. The thermal imagers with the smallest SSE were imager $F$, the research grade cooled InSb thermal imager, and imager $E$. The measurement area of imager $F$ was amongst the smallest $(<4 \mathrm{~mm}$ diameter at $1.0 \mathrm{~m})$ and should therefore provide a small SSE when compared to imager $D$ which has a set measurement area of $13 \mathrm{~mm}$ diameter at $1.0 \mathrm{~m}$. However, imagers $A$ and $B$ also had a measurement area $<4 \mathrm{~mm}$ diameter but suffered from the largest SSE. This could be caused by diffractions, scatter and reflections due to the internal optics of the thermal imager (described in references [4,6,7]).

To provide a more quantitative illustration of the SSE, the results for imagers A and $F$ are also expressed in terms of temperature differences (difference between the blackbody source and the indicated imager temperatures) and are given in table 5. 
Table 5 SSE results for imager $\mathrm{F}$ (left) and imager A (right) at $900^{\circ} \mathrm{C} . \Delta T=T 90-T_{\text {imager }}$.

\begin{tabular}{|c|c|c|c|c|c|}
\hline $\begin{array}{c}\text { Aperture } \\
\text { diameter / mm }\end{array}$ & $\Delta \mathbf{T} /{ }^{\circ} \mathbf{C}$ & SSE & $\begin{array}{c}\text { Aperture } \\
\text { diameter / mm }\end{array}$ & $\Delta \mathbf{T} /{ }^{\circ} \mathbf{C}$ & SSE \\
\hline 4 & 27.4 & 0.9090 & 4 & 258.4 & 0.6496 \\
\hline 6 & 21.9 & 0.9328 & 6 & 106.4 & 0.8660 \\
\hline 8 & 18.0 & 0.9495 & 8 & 76.1 & 0.9103 \\
\hline 10 & 14.2 & 0.9644 & 10 & 58.1 & 0.9368 \\
\hline 12 & 12.0 & 0.9735 & 12 & 47.8 & 0.9521 \\
\hline 15 & 9.3 & 0.9848 & 15 & 36.1 & 0.9694 \\
\hline 20 & 7.8 & 0.9915 & 20 & 25.8 & 0.9841 \\
\hline 25 & 6.7 & 0.9956 & 25 & 20.5 & 0.9926 \\
\hline 30 & 5.7 & 1.0000 & 30 & 15.5 & 1.0000 \\
\hline
\end{tabular}

The results of the low temperature SSE tests are comparable to the high temperature SSE results. Again imager E had one of the smallest SSES, whilst imager B had the worst of the imagers tested. At lower temperatures the SSE of imager $\mathrm{F}$ had increased, such that the effect of measured temperature with changing aperture diameter was greater than when similar measurements were made at $900{ }^{\circ} \mathrm{C}$, which as stated earlier regarding the repeatability could be due to a poor signal to noise ratio at low temperatures.

\subsection{Warm-up effect}

The warm-up effect at high and low source temperature is shown in figures 7 and 8 respectively.

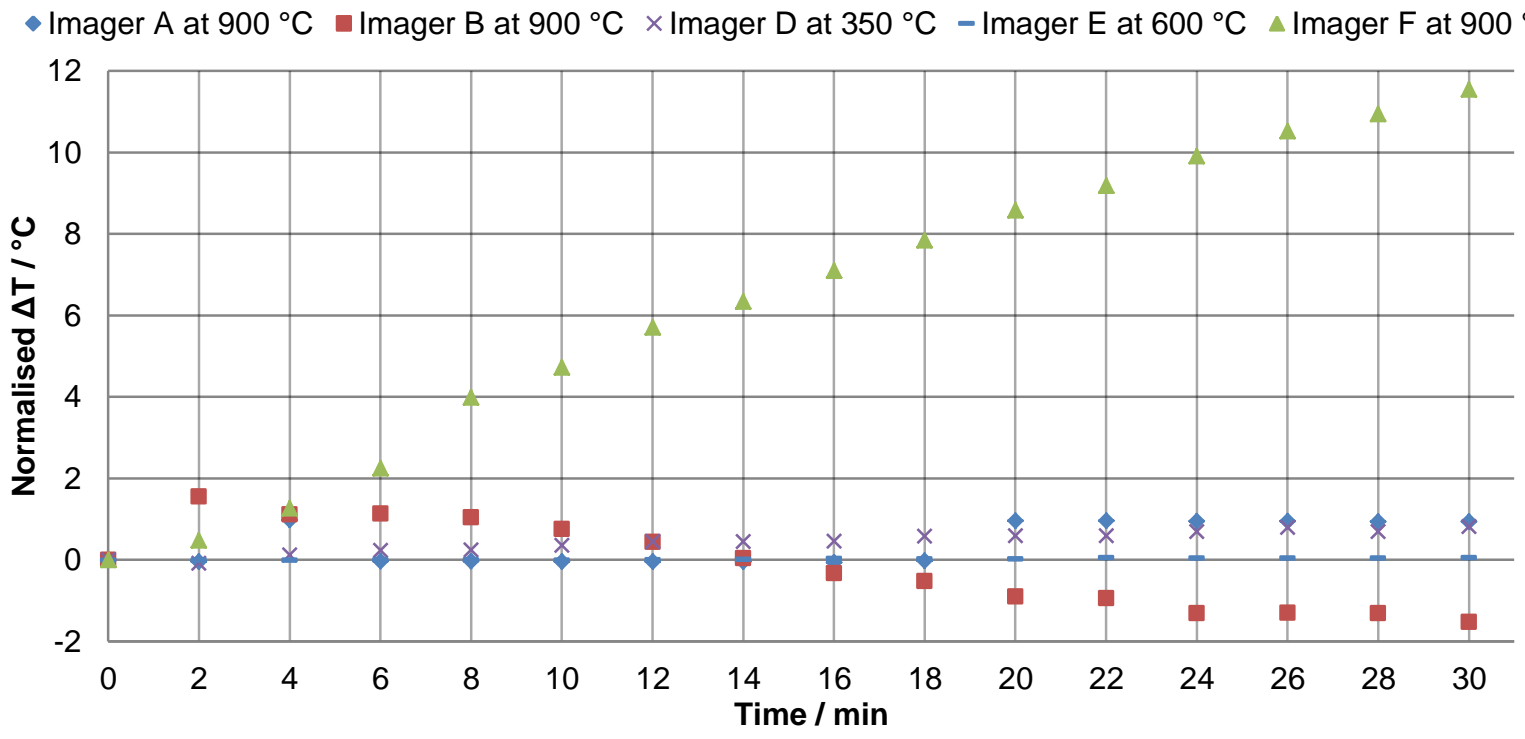

Fig. 7 Measurement of thermal imager's drift over a 30 minute period after 'switch on'.

There was a noticeable variation in the drift of the imager readings following switch-on. At high temperature imager $\mathrm{F}^{4}$ drifted continually for over 60 minutes by more than $15^{\circ} \mathrm{C}$ at which point measurements were stopped. These findings may suggest that the drift is caused by heating of the cooled InSb detector from the blackbody at $900{ }^{\circ} \mathrm{C}$, as the effect was not as prominent in the imagers with uncooled detectors. This drift could also be responsible for the large difference in repeat readings found using imager $F$ at high temperatures if the imager had been viewing the high temperature source for different lengths of time before measurements were made (i.e. to align the thermometer on the centre of the aperture, set the correct distance and viewing angle). Imager $\mathrm{E}$ showed no drift over the 30 minute period (source temperature of $600{ }^{\circ} \mathrm{C}$ ), while imager $\mathrm{A}$ changed by $1.0^{\circ} \mathrm{C}$ over the measurement time (source temperature $900{ }^{\circ} \mathrm{C}$ ). However these measurements are limited by the temperature resolution of $1.0{ }^{\circ} \mathrm{C}$ for both these imagers. Imager $\mathrm{D}$ drifted upwards, closer to the source temperature, by $0.9^{\circ} \mathrm{C}$ over a 30 minute period, whilst the indicated temperature of imager B decreased, further away from the source temperature, over the 30 minutes by $3.7^{\circ} \mathrm{C}$. The different results found for different thermal imagers suggest that manufacturers are using different temperature compensation algorithms for the heating effects from both the ambient temperature compensation and detector temperature.

\footnotetext{
${ }^{4}$ Time was allowed for the InSb detector to be fully cooled before any measurements were made.
} 
When the same test was repeated but at temperatures below ambient (see figure 8) the temperature drift of imager $\mathrm{F}$ was much lower: only $2.7^{\circ} \mathrm{C}$ over 30 minutes compared to $11.6{ }^{\circ} \mathrm{C}$ over 30 minutes at $900{ }^{\circ} \mathrm{C}$. The displayed temperature of imager $\mathrm{F}$ also decreased, away from the source temperature, over the measurement period, as did imagers $\mathrm{B}$ and $\mathrm{D}$ by $2.0^{\circ} \mathrm{C}$ and $1.6^{\circ} \mathrm{C}$ respectively. The displayed temperatures of imagers $\mathrm{A}$ and $\mathrm{E}$ both increased over the 30 minute period after switch on by $1.0^{\circ} \mathrm{C}$. As mentioned above this drift could be attributed to a variation in temperature compensation techniques used by different manufacturers. At lower target temperatures this is not particularly an issue but, at higher temperatures, the amount of drift is not insignificant for devices being used for quantitative temperature measurement. It should also be noted that some of the imagers drift initially (on switch-on) but then stabilise after a period of around 10 minutes or so. It is also important to note that during the calibration and all other tests the thermal imagers were switched on for a minimum of 2 hours before any measurements were made.

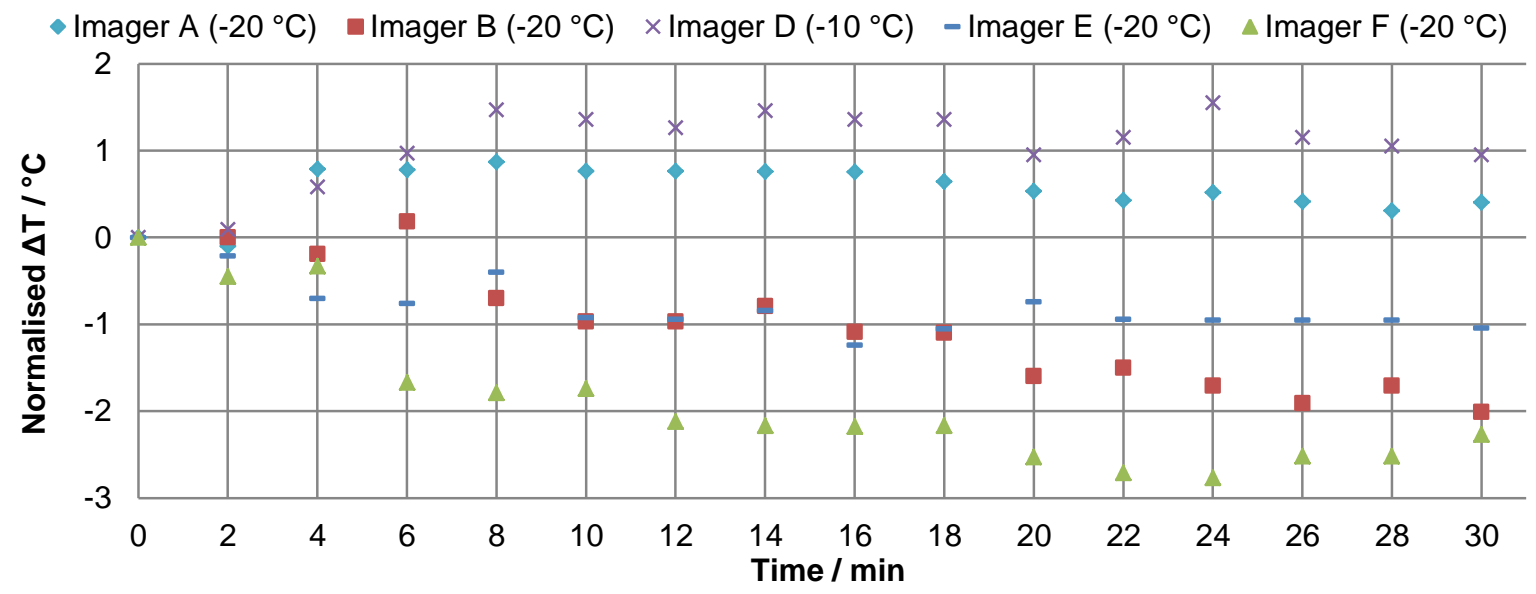

Fig. 8 Measurement of thermal imager's drift over a 30 minute period after 'switch on', imager's minimum measureable temperature.

\subsection{Image non-uniformity}

The results of the measurements from the 17 points taken over each thermal imager's (imagers A, B, E and F) full FOV at $0.5 \mathrm{~m}$ from the target blackbody are represented in figure 9 . The temperatures are the average temperatures indicated by the measurement region in each position. The blackbody source was stable to within $0.2^{\circ} \mathrm{C}$ over the duration of the measurements made with each imager. The non-uniformity patterns seen are similar to those found by Miklavec et al [5], as there is a greater non-unformity (larger difference from the central temperature reading) towards the edges of the FOV, particularly in the corners. However, as the NPL tests have been conducted at higher temperatures $\left(600{ }^{\circ} \mathrm{C}\right.$ and $900{ }^{\circ} \mathrm{C}$ compared with $70^{\circ} \mathrm{C}$ in [5]) the observed non-uniformity is much greater.

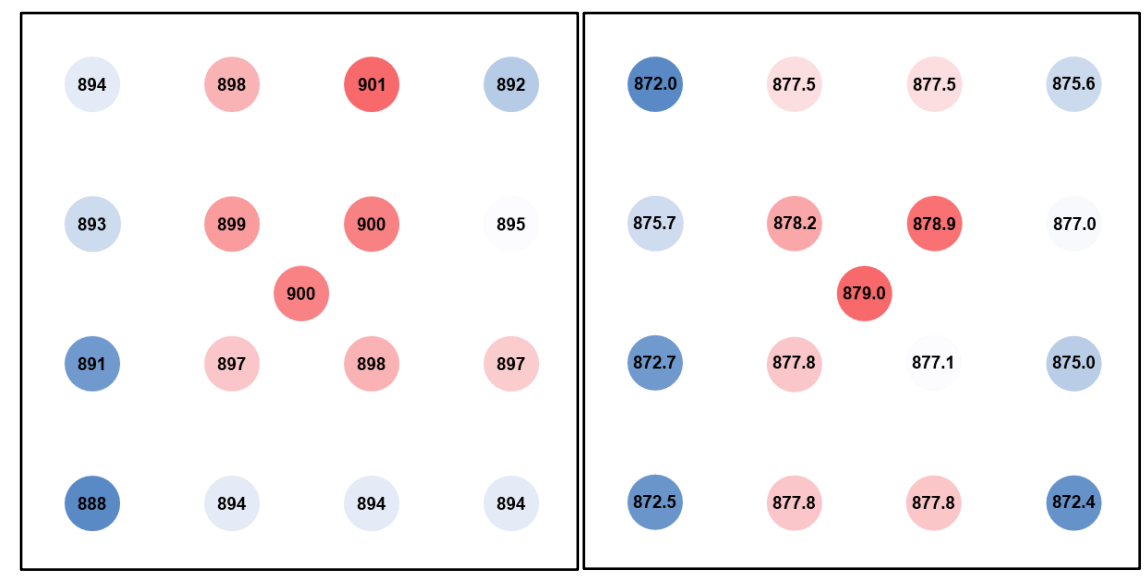




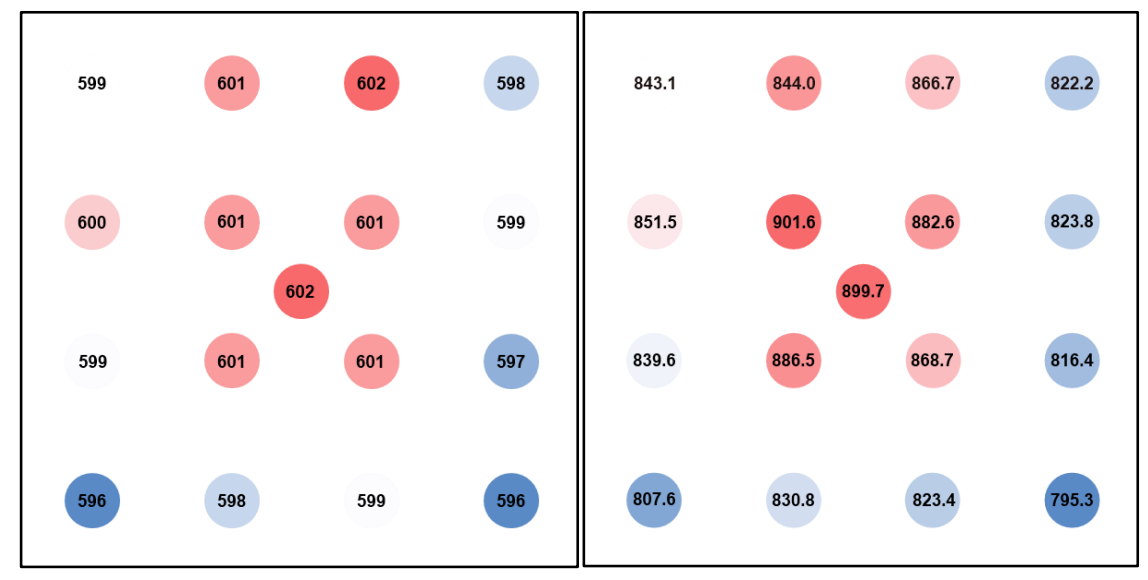

Fig. 9 Non-uniformity results of imager's A (top left), B (top right), E (bottom left) and F (bottom right)

The results of the non-uniformity measurements of the thermal imagers showed a large variation between imagers. Imager $A$ was found to have a maximum non-uniformity of $13^{\circ} \mathrm{C}$ over the full FOV, imager $B$ had a maximum nonuniformity of $7{ }^{\circ} \mathrm{C}$, and imager $\mathrm{E}$ showed a maximum non-uniformity of $6{ }^{\circ} \mathrm{C}$ (at $600{ }^{\circ} \mathrm{C}$ ). Imager $\mathrm{F}$ had the worst nonuniformity of all the thermal imagers, with a maximum non-uniformity of $106{ }^{\circ} \mathrm{C}$. Even measurement areas near the centre of imager F's FOV had a non-uniformity of $31^{\circ} \mathrm{C}$, considerably more than the manufacturer's stated uncertainty of $\pm 9{ }^{\circ} \mathrm{C}$ at $900{ }^{\circ} \mathrm{C}$.

\subsection{Ambient conditions}

The effect of changing ambient temperature had little effect on the temperature reading of any of the thermal imagers when laboratory temperature was varied between $18{ }^{\circ} \mathrm{C}$ and $25^{\circ} \mathrm{C}$. Any changes in imager reading measured during these tests would most likely have resulted from the repeatability of the thermal imagers and fell within the uncertainty of the instrument. By carrying out these measurements within an environmental chamber, as shown by Vendt et al [8], a greater range of ambient temperatures could be assessed.

\section{Conclusion}

The temperature measurement performance of a range of thermal imagers has been tested to assess their suitability for quantitative temperature measurements. The results of the calibration show that the temperature readings of some imagers fall outside the accuracy limits given by the manufacturer, and further that the image uniformity can be poor. The tests investigating the effect of changing working distance and source size show that some imagers are significantly influenced by changes in these parameters and this has implications when they are being used for quantitative temperature measurements under conditions that are different to those during the calibration. Limited changes in ambient temperature showed no significant change in measurement temperature for any of the thermal imagers, but with tests only being carried out over an environmental temperature range of $18{ }^{\circ} \mathrm{C}$ to $25^{\circ} \mathrm{C}$ it is not possible to confirm as to whether discrepancies would occur over a wider temperature range.

\section{References}

[1] Preston-Thomas H 1990, "The International Temperature Scale of 1990(ITS-90)". Metrologia, vol. 27, pp. 3-10, 1990

[2] Mcevoy H, Simpson R and Machin G "Review of current thermal imaging temperature calibration and evaluation facilities, practices and procedures, across EURAMET ". Proc. of QIRT, vol 9, paper 334, 2012

[3] Machin $\mathrm{G}$ and Chu B, "High-quality blackbody sources for infrared thermometry and thermography between $-40^{\circ} \mathrm{C}$ and $100{ }^{\circ} \mathrm{C} "$. Imaging Sci., vol. 48, pp. 15-22, 2000

[4] Bloembergen P, Duan Y, Bosma R and Yuan Z, "The characterization of radiation thermometers subject to the size-of-source effect". Proc. of TEMPMEKO, vol 96, pp. 261-266, 1996

[5] Miklavec A, Pušnik I, Batagelj V and Drnovšek J, "Calibration of Thermal Imagers by Evaluation of the Entire Field-of-View". Int. J. Thermophys., vol. 32, pp. 2600-2609, 2011

[6] Ricolfi T and Li W, "Experiments and remarks on the size-of-source effect in precision radiation thermometry". Proc. TEMPMEKO '93, vol. V, pp. 161-165, 1996

[7] Machin G and Ibrahim M, "Size of source effect and temperature: I - High temperature systems". Proc. TEMPMEKO '99, vol. VII, pp. 681-686, 1999

[8] Vendt R, Juurma M, Jaanson P, Vabson V, Kübarsepp T and Noorma M, "Effects of Environmental Conditions on the Performance of Thermal Imagers". Int. J. Thermophys., vol 32, pp 248-257, 2011 